\title{
Erratum to: Genetic and Histopathological Responses to Cadmium Toxicity in Rabbit's Kidney and Liver: Protection by Ginger (Zingiber officinale)
}

\author{
Ahmed A. Baiomy ${ }^{1,2} \cdot$ Ahmed A. Mansour ${ }^{1,3}$
}

Published online: 6 November 2015

(C) Springer Science+Business Media New York 2015

Erratum to: Biol Trace Elem Res (2015)

DOI 10.1007/s12011-015-0491-4

The authors wish to indicate the following corrections to the referenced article.

1- In the original Abstract lines [7 and 8], the value [200 mg/ $\mathrm{kg}]$ was incorrect. It should have been $[20 \mathrm{mg} / \mathrm{kg}]$.

2- In the original Materials and Methods lines [11 and 12], the value $[200 \mathrm{mg} / \mathrm{kg}]$ was also incorrect; it should have been $[20 \mathrm{mg} / \mathrm{kg}]$.

The authors regret the oversight.

The online version of the original article can be found at http://dx.doi.org/ 10.1007/s12011-015-0491-4.

Ahmed A. Mansour

ahmedmansour292@gmail.com

1 Department of Medical Biotechnology, Faculty of Applied Medical Sciences, Taif University, Turabah, Saudi Arabia

2 Department of Zoology, Faculty of Science, Cairo University, Giza, Egypt

3 Department of Genetics, Faculty of Agriculture, Ain Shams University, Cairo, Egypt 